\title{
Pelatihan pengembangan animasi pembelajaran matematika dalam membentuk karakter menghadapi revolusi 5.0
}

\author{
Nurapni Sopia*, Melinda Rismawati, Olenggius Jiran Dores \\ STKIP Persada Khatulistiwa Sintang \\ Email Korespondensi: " nurapni22sopia@gmail.com.id
}

Received September 24, 2021; Revised October 13, 2021; Accepted October 14, 2021

\begin{abstract}
Abstrak
Pada zaman sekarang sangat dibutuhkan teknologi informasi dan komunikasi yang telah menjamah keseluruh ranah kehidupan dan semua kalangan. Salah satu fakta yang ada terdapat pada siswa yang lebih tertarik untuk bermain smartphone daripada membaca buku. Dari segi guru matematika belum memiliki kompetensi dan kreativitas untuk membuat pembelajaran yang menyenangkan. Penyelesaian permasalahan tersebut diwujudkan melalui kegiatan pelatihan singkat mengenai pengembangan animasi pembelajaran matematika dalam membentuk karakter menghadapi revolusi 5.0 yang dilanjutkan dengan proses pendampingan bagi guru dalam mengembangkan media pembelajaran berbasis animasi. Kegiatan ini dilaksanakan untuk mengatasi kesulitan siswa dalam memahami materi dan konsep dalam matematika, membangun karakter siswa SD, meningkatkan kompetensi dan keterampilan guru SD sekota Sintang.
\end{abstract}

Kata Kunci: Pelatihan; Pengembangan Animasi Pembelajaran; Karakter

\begin{abstract}
In this day and age, information and communication technology is urgently needed which has touched all aspects of life and all walks of life. One of the facts is that students are more interested in playing smartphones than reading books. In terms of mathematics teachers do not have the competence and creativity to make learning fun. The solution to these problems is realized through short training activities regarding the development of animation in mathematics learning in shaping characters to face the 5.0 revolution, which is followed by a mentoring process for teachers in developing animation-based learning media. This activity was carried out to overcome students' difficulties in understanding materials and concepts in mathematics, build the character of elementary school students, improve the competence and skills of elementary school teachers in Sintang.
\end{abstract}

Keywords:Training; Development of Learning Animation; Character

\section{PENDAHULUAN}

Sumber daya manusia yang berdaya saing tinggi dan berkualitas harus dipersiapkan melalui pendidikan bermutu agar menghasilkan generasi yang mampu menghadapi revolusi industri 5.0. Oleh karena itu, agar pendidikan bermutu perlu adanya upaya guru dalam merancang pembelajaran sehingga siswa dapat melakukan kegiatan pembelajaran dengan memanfaatkan teknologi yang sedang berkembang saat ini. Hal ini sejalan dengan [1]Arjunaita yang mengatakan bahwa para guru dituntut menguasai keahlian, kemampuan beradaptasi dengan teknologi baru dan tantangan global [2]sehingga professional guru sangat penting. ${ }^{[3]}$ Teknologi informasi dan komunikasi atau TIK pada zaman sekarang sangat dibutuhkan oleh setiap masyarakat baik itu orang dewasa maupun anak-anak. Pada dasarnya pengaruh perkembangan teknologi telah menjamah keseluruh ranah kehidupan dan semua kalangan. Salah satu fakta yang ada terdapat pada siswa SD Negeri 20 SKP G SP 1 Emparu dengan jumlah rombel sebanyak 6 yang terdiri dari siswa laki-laki 111 orang dan perempuan 90 orang dengan total keseluruhan siswa berjumlah 201 orang mayoritas lebih tertarik untuk bermain gadget daripada membaca buku. Hal ini akan menjadi permasalahan bagi guru yang mengajar di sekolah tersebut dengan jumlah 10 orang yang terdiri dari 6 orang guru PNS dan 4 orang guru Non PNS. Akibatnya, siswa mengalami kendala untuk melakukan proses belajar dalam kegiatan pembelajaran ditambah lagi dengan materi yang sulit dan kurang menarik. Khususnya mata pelajaran matematika, sebagian besar siswa memiliki persepsi bahwa matematika cukup sulit untuk dipelajari. 
Berdasarkan hasil wawancara terhadap kepala sekolah, ada beberapa faktor yang mengakibatkan matematika dianggap sulit diantaranya yakni sebesar 11,35\% guru matematika belum memiliki kompetensi dan kreativitas dalam pengajaran yang optimal, sehingga ketika pertanyaan kritis diajukan oleh siswa, mereka tidak mampu menjawab terlihat pada gambar 1 . Selain itu, penguasaan materi prasyarat yang kurang menyebabkan siswa kesulitan dalam memahami matematika dan kesan negatif siswa dalam belajar matematika akan mempengaruhi motivasi siswa dalam proses belajar selanjutnya. Pengalaman sebelumnya terhadap matematika menjadi prediktor yang kuat terhadap kesuksesan pada masa berikutnya. Kesulitan yang dialami siswa bisa jadi penyebab siswa kurang termotivasi sehingga prestasi belajar siswa kurang bahkan tidak memuaskan berdampak pada karakter siswa yang semakin menurun.
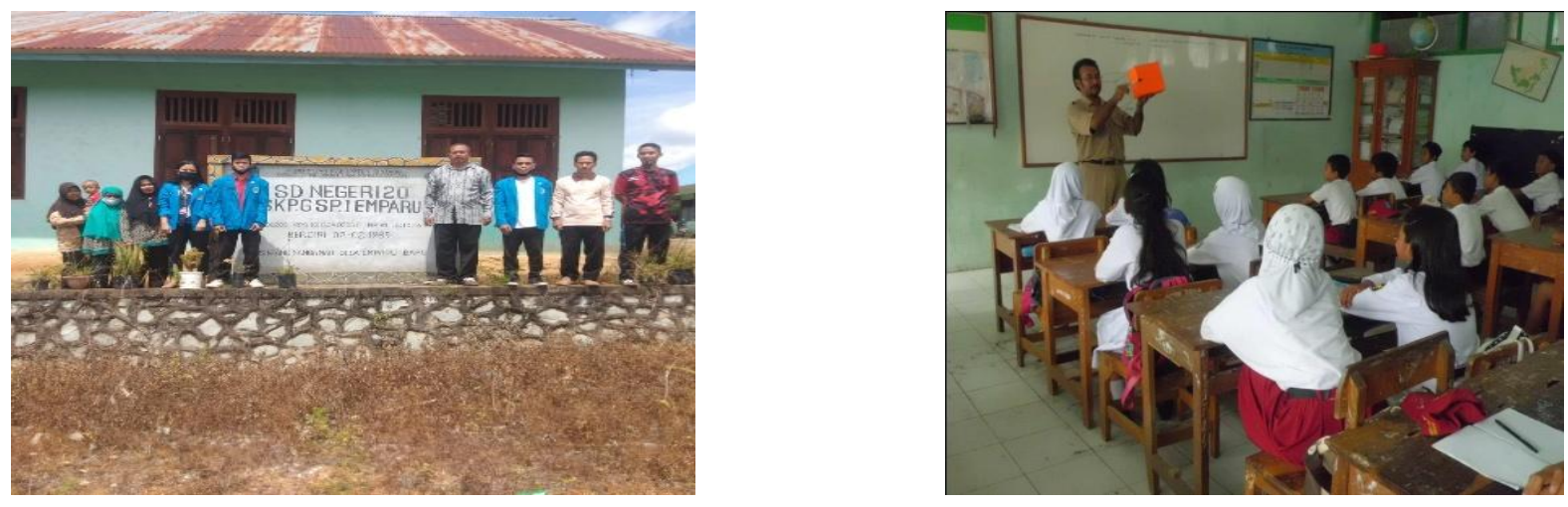

Gambar 1. Lokasi dan kegiatan pembelajaran matematika yang telah dilaksanakan di SD Negeri 20 SKP G SP 1 Emparu.

Upaya mengatasi hal tersebut perlu adanya kebiasaan berpikir positif sehingga menjadi keterampilan yang baik pula dalam menyelesaikan masalah sehingga terbentuklah perwujudan karakter. Rufaida mengungkapkan bahwa dengan berpikir positif akan memunculkan: optimis, harapan positif, berbaik sangka (khusnudzan), mengambil hikmah (pelajaran) dari setiap peristiwa[4]. Persoalan karakter, merupakan kajian dari pengembangan Kurikulum 2013 yang diterapkan agar menghasilkan lulusan yang bukan hanya mampu mengembangkan kemampuan kognitif, afektif, maupun psikomotoriknya, akan tetapi pengembangan dari kemampuan ketiganya menjadi karakter yang baik dan dapat dibentuk dari perbuatan positif.

Oleh sebab itu, untuk membangun karakter siswa perlu adanya peran guru dalam pengembangan kompetensi dan kreativitas. Guru harus memiliki kreativitas agar mampu membuat inovasi dalam pembelajaran. Pembelajaran yang baik adalah pembelajaran yang dapat meningkatkan kemampuan berpikir HOTS dan kreativitas siswa serta pembelajaran yang baik adalah pembelajaran yang memberikan kesempatan kepada siswa untuk aktif dalam membangun pengetahuannya sendiri[5][6][7][8]. Pembelajaran harus dirancang agar siswa merasa senang dan nyaman ketika belajar. Salah satu upaya guru untuk mewujudkan hal tersebut yakni dengan menggunakan media pembelajaran yang mampu untuk memvisualisasikan materi, sehingga proses pembelajaran lebih optimal dan dapat memudahkan siswa dalam memahami konsep yang dipelajari. Media pembelajaran adalah salah satu alat komunikasi yang digunakan oleh guru untuk menyampaikan materi kepada siswa[9].

Oleh sebab itu, pengembangan media pembelajaran harus terus diinovasi agar memberikan manfaat yang optimal. Pengembangan yang telah dilakukan memberikan dampak positif dalam pembelajaran sehingga dapat memberikan hasil belajar yang lebih baik. Salah satu media pembelajaran yang dapat membantu proses belajar mengajar adalah video animasi. Media audio visual, yang diharapkan mampu menjadi media pembelajaran yang menarik, interaktif, dan menambah semangat belajar siswa sehingga diharapkan ada perbaikan nilai dan pengetahuan siswa[10].

Media pembelajaran berbasis animasi bertujuan agar dapat menambah ketertarikan siswa untuk belajar. Animasi memiliki kemampuan untuk dapat memaparkan sesuatu yang rumit atau kompleks dan sulit untuk dijelaskan dengan hanya gambar dan kata-kata saja. Animasi juga dilengkapi dengan audio sehingga dalam pembelajaran siswa dapat memaksimalkan gaya belajar mereka masing-masing. Mengembangkan media pembelajaran berbasis animasi dapat digunakan untuk menjelaskan suatu materi yang tidak dapat terlihat oleh mata secara nyata dengan cara melakukan visualisasi sehingga materi yang dijelaskan dapat tergambarkan. Media pembelajaran berbasis animasi sangat bermanfaat bagi guru dalam kegiatan pembelajaran. Hal ini dapat diketahui dengan berbagai hasil beberapa pengabdi yakni yang menyatakan bahwa media pembelajaran 
interaktif berbasis animasi layak digunakan[11]. Berdasarkan pemaparan hasil mengenai media animasi dan hasil pengabdian yang menunjukkan bahwa pembelajaran animasi efektif digunakan untuk mengatasi kesulitan siswa dalam memahami materi dan konsep dalam matematika, membangun karakter siswa SD, meningkatkan kompetensi dan keterampilan guru.

\section{METODE}

Kegiatan Pengabdian Kepada Masyarakat (PkM) ini dilaksanakan selama 1 semester. Adapun metode pelaksanaan kegiatan PkM disajikan pada alur pada gambar 2.

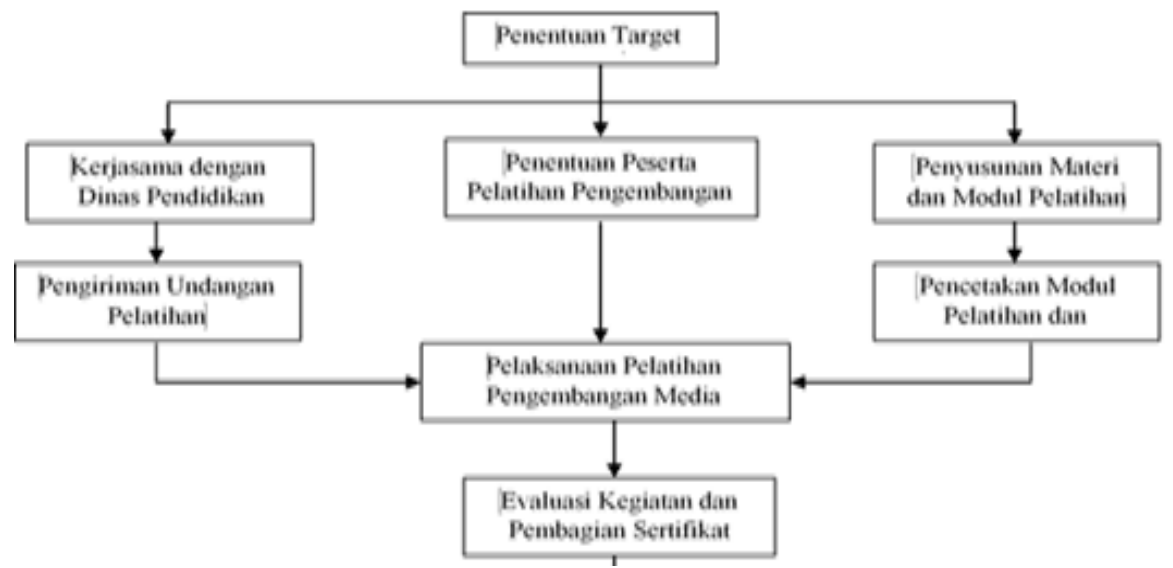

Gambar 2. Alur Pelaksanaan Kegiatan PkM

Pada kegiatan PkM yang akan dilaksanakan mengikuti tahapan sebagai berikut: 1) Tahap Persiapan, dimana sebelum pelaksanaan kegiatan $\mathrm{PkM}$ berlangsung, Tim pengabdi melakukan rapat koordinasi dan musyawarah untuk membentuk kepanitian. Setelah terbentuk kepanitian, ketua panitia selanjutnya melakukan pembagian tugas sesuai dengan job description yang telah diputuskan. 2) Tahap Pelaksanaan, PkM Tim pengusul yang telah direncanakan, berlangsung selama 1 Semester dengan metode yang dilakukan yaitu metode pelatihan serta metode pendampingan. Guru-Guru SD sekota Sintang mendapatkan praktik langsung serta pendampingan oleh Tim pengabdi, para guru juga diminta untuk membuat desain rencana produksi media pembelajaran sesuai dengan materi dan kompetensi masing-masing. Pembuatan media pembelajaran berbasis animasi ini dipandu oleh Nurapni Sopia, M.Pd sebagai praktisi utama dengan bidang keahlian Pendidikan Matematika, yang akan dibantu oleh Tim pengabdi lainnya sebagai pendukung dalam menjelaskan materi matematika sesuai bidang keahlian Pendidikan Matematika kepada peserta pelatihan pengembangan media pembelajaran interaktif berbasis animasi; dan 3) Tahap evaluasi PkM dilaksanakan dengan pengamatan langsung dan memberikan quesioner sebelum dan setelah pelatihan pengembangan media pembelajaran interaktif berbasis animasi diawal dan diakhir pertemuan yang bertujuan untuk mengetahui kualitas kompetensi dan kreatifitas setiap guru. Pada kegiatan ini maka diperlukan kembali pelatihan pengembangan media pembelajaran interaktif berbasis animasi, karena kemampuan ini sangat diperlukan oleh seorang guru dan perlu diperkuat kembali secara berulang-ulang. Selain itu kegiatan dengan tema penambahan wawasan guru dengan informasi alternatif bentuk media lainnya yang inovatif, mutlak diperlukan.

Metode kegiatan yang dilakukan yaitu ceramah, diskusi, dan praktik. Kegiatan pengabdian dibulan pertama memfokuskan dalam memberikan informasi mengenai pengenalan media pembelajaran interaktif berbasis animasi, dasar pembuatan animasi sederhana dan pembuatan naskah produksi sebuah media pembelajaran, dimana peserta langsung membuat project sendiri. Pada bulan kedua dan ketiga, pelatihan akan memfokuskan terhadap pengembangan animasi, menggunakan berbagai metode dan action script/bahasa pemrograman sederhana kemudian diakhir pelatihan akan diadakan evaluasi kepada peserta pelatihan. Peserta dibekali dengan modul pelatihan pengembangan media interaktif berbasis animasi yang digunakan sebagai alat bantu dalam kegiatan praktik.

Kegiatan ini dimulai dengan menganalisis situasi dan permasalahan yang dihadapi oleh mitra, Solusi yang ditawarkan kepada mitra adalah dengan transfer IPTEKS berupa pelatihan pembuatan media pembelajaran berbasis animasi, serta dilakukan pendampingan kepada pihak mitra. Adapun skema kegiatan dalam mengatasi permasalahan mitra dapat dilihat pada gambar 3. 


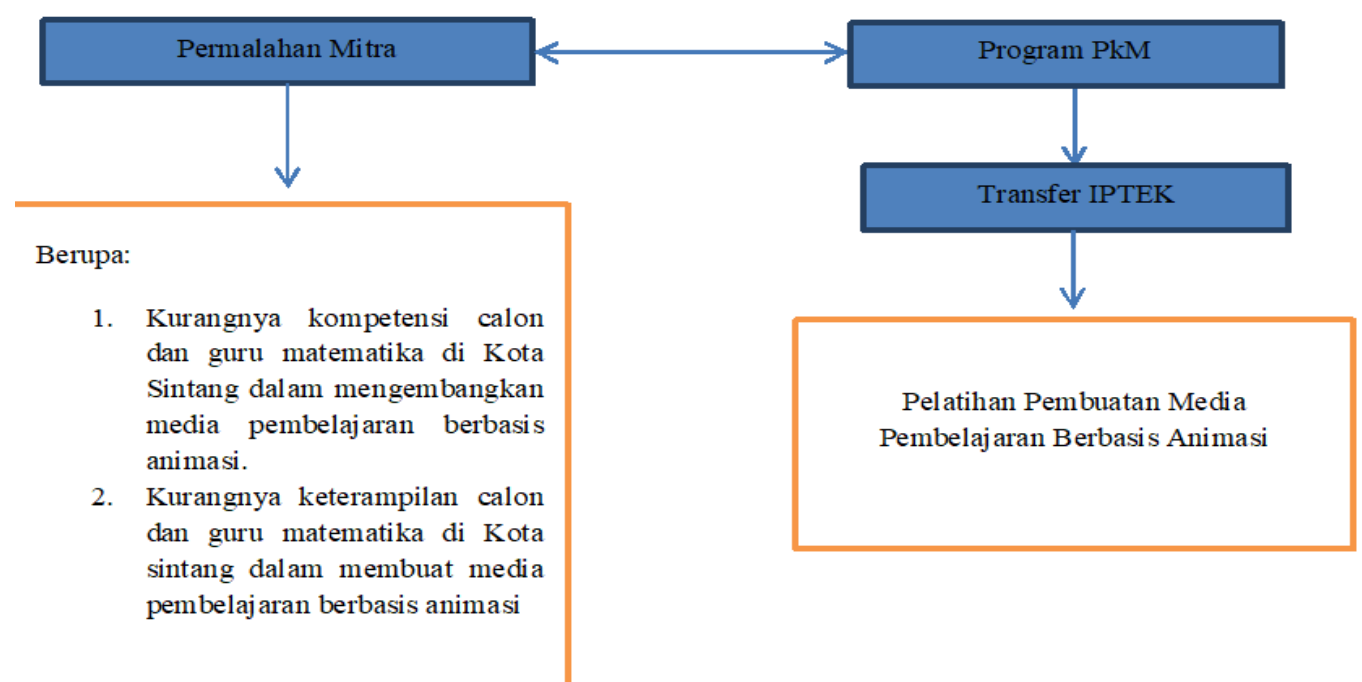

Gambar 3. Desain Mengatasi Permasalahan Mitra

\section{HASIL DAN PEMBAHASAN}

Kegiatan PkM dalam bentuk Pelatihan yang berjudul "Pelatihan Pengembangan Animasi Pembelajaran Matematika dalam Membentuk Karakter Menghadapi Revolusi 5.0" diselenggarakan melalui Zoom Meet. Adapun pertemuan dilakukan dengan menyampaikan materi menggunakan dua metode yaitu metode ceramah dan demonstrasi. Materi disampaikan dalam bentuk slide presentasi sederhana dan demontrasi beberapa media pembelajaran berbasis animasi. Kegiatan pada hari pertama dimulai pukul 09.00 WIB yang diawali dengan acara pembuka oleh Venny Averon yakni mahasiswa Program Studi Pendidikan Matematika Angkatan ke-3. Kemudian kata sambutan dari ketua STKIP Persada Khatulistiwa Sintang sekaligus membuka secra resmi kegiatan pelatihan seperti yang terlihat pada gambar 4.

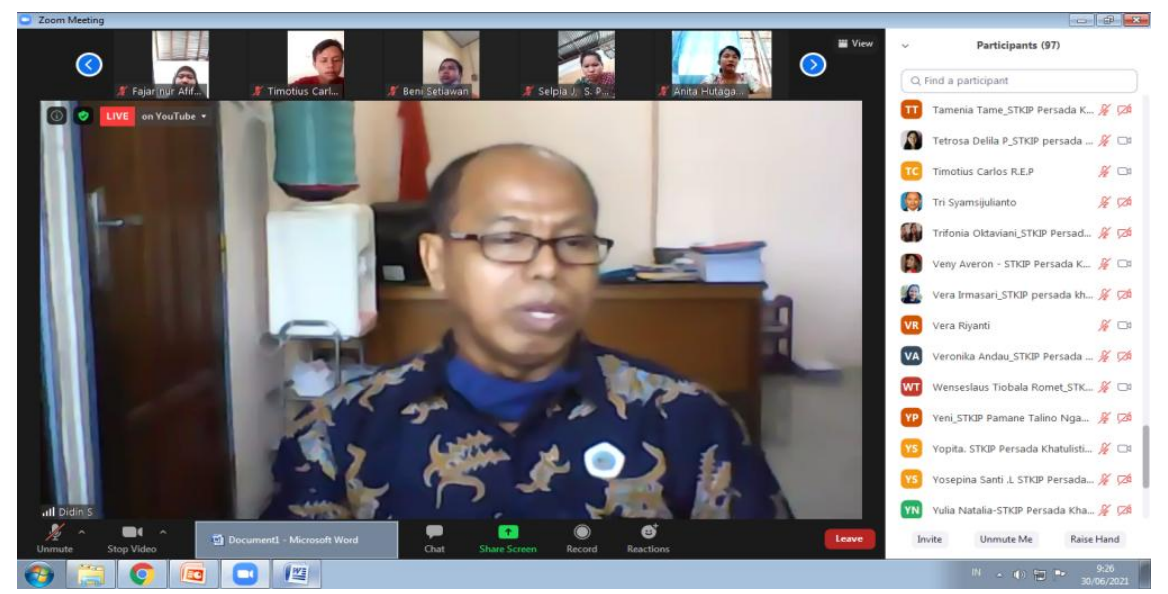

Gambar 4. Sambutan Ketua STKI Sekaligus Membuka Secara Resmi Kegiatan Pelatihan

Kegiatan selanjutnya, pemaparan materi yang dipandu oleh Ibu Melinda Rismawati, M.Pd mengenai pembelajaran matematika yang menyenangkan. Materi pertama adalah Pengembangan Pembelajaran Matematika Menghadapi Revolusi 5.0 yang disampaikan oleh Olenggius Jiran Dores, M.Pd. Materi tersebut berisi Pengembangan yang telah dilakukan berupa metode, dan teknik dalam pembelajaran matematika serta teknik pengembangan pembelajaran matematika mehadapi revolusi 5.0. Materi ini sekaligus memberikan gambaran awal kepada masyarakat. 


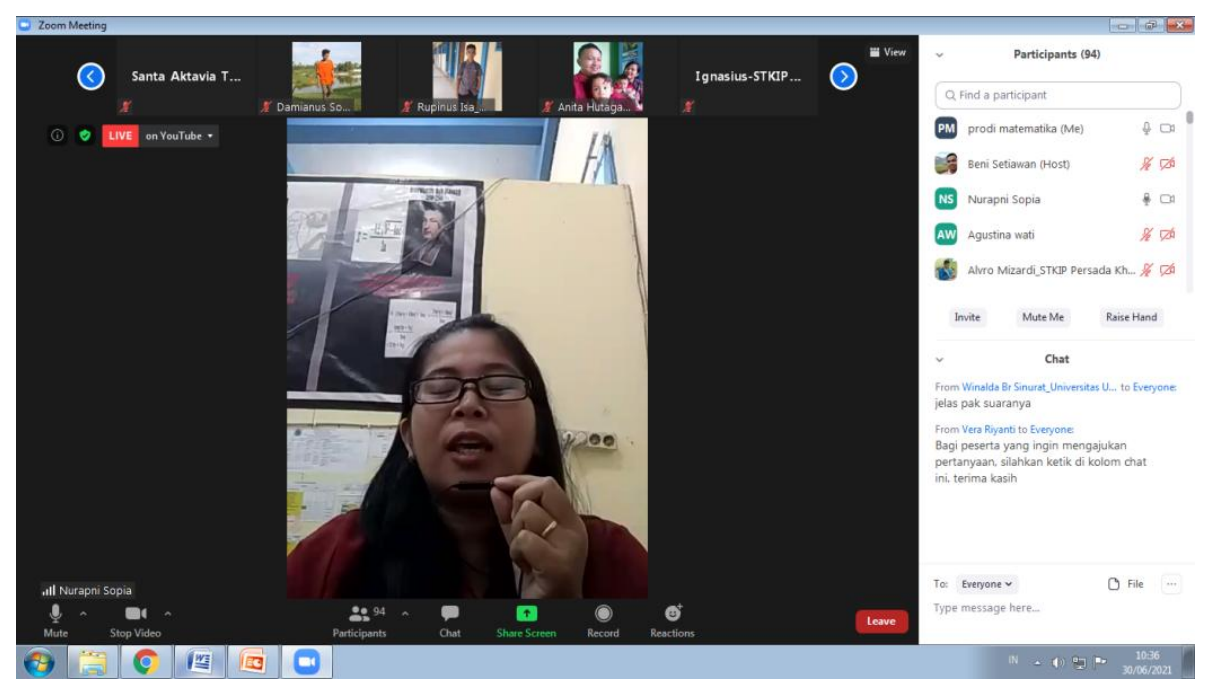

Gambar 5. Penyampaian materi Pengembangan Animasi dalam Membentuk Karakter

Pada gambar 5, merupakan penyampaikan materi selanjutnya, Pengembangan Animasi dalam Membentuk Karakter yang dipaparkan oleh Nurapni Sopia, M.Pd. Isi materi ini adalah menyampaikan kepada masyarakat agar kreatif dalam menggunakan aplikasi PC maupun android untuk pengembangan animasi pembelajaran matematika dan pembentukan karakter melalui animasi yang diberikan guna menghadapi revolusi 5.0. Adapun demontrasi animasi dapat dilihat pada gambar 6.

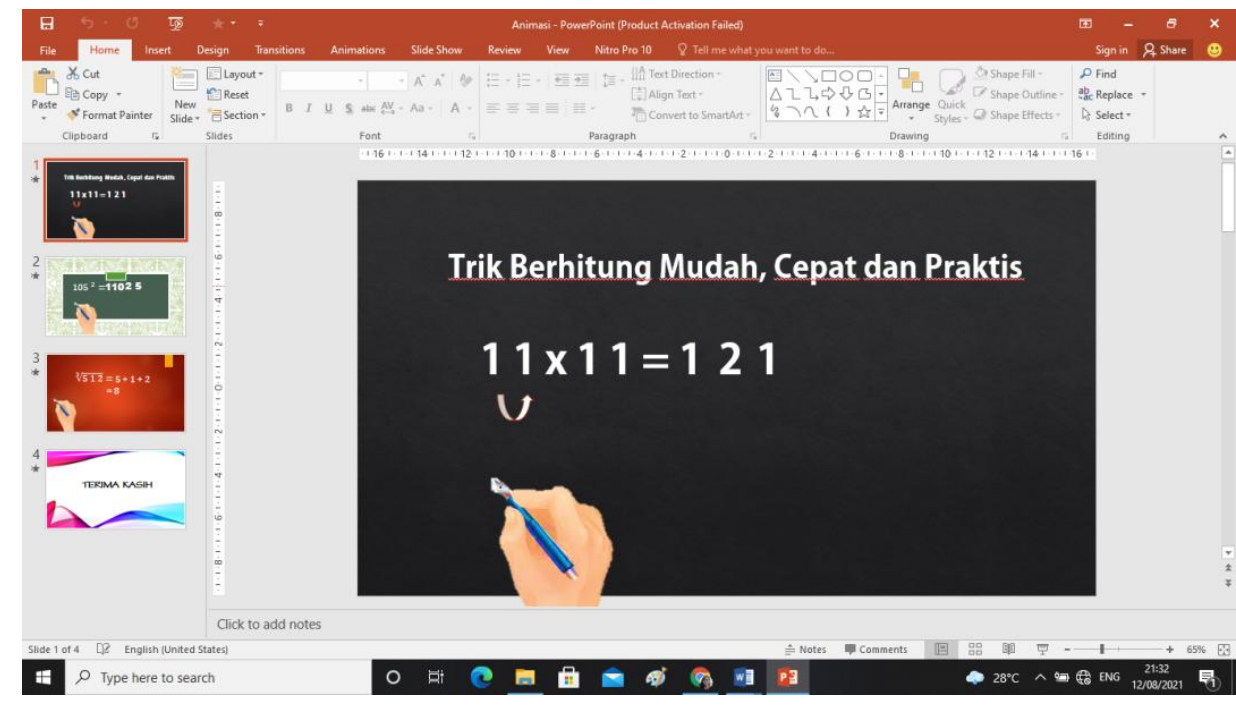

Gambar 6. Sebagian Tampilan Animasi Pembelaran Matematika

Kemudaian sesi diskusi. Selanjutnya kegiatan diakhiri dengan kalimat penutup yang dilakukan oleh pembawa acara. Adapun tindak lanjut dari kegiatan yaitu latihan/praktik dengan memanfaatkan berbagai aplikasi baik berbasis android maupun PC sebagai media pembelajaran matematika. Kegiatan ini dilaksanakan selama satu hari yaitu pada hari Rabu, 30 Juni 2021 dengan jumlah peserta yang hadir dalam kegiatan yaitu sebanyak 172 peserta yang terdiri dari guru dan dan calon guru se kota Sintang. Kegiatan berlangsung tertib dan peserta penuh antusias dalam melaksanakan pelatihan terlihat pada gambar 7 . 

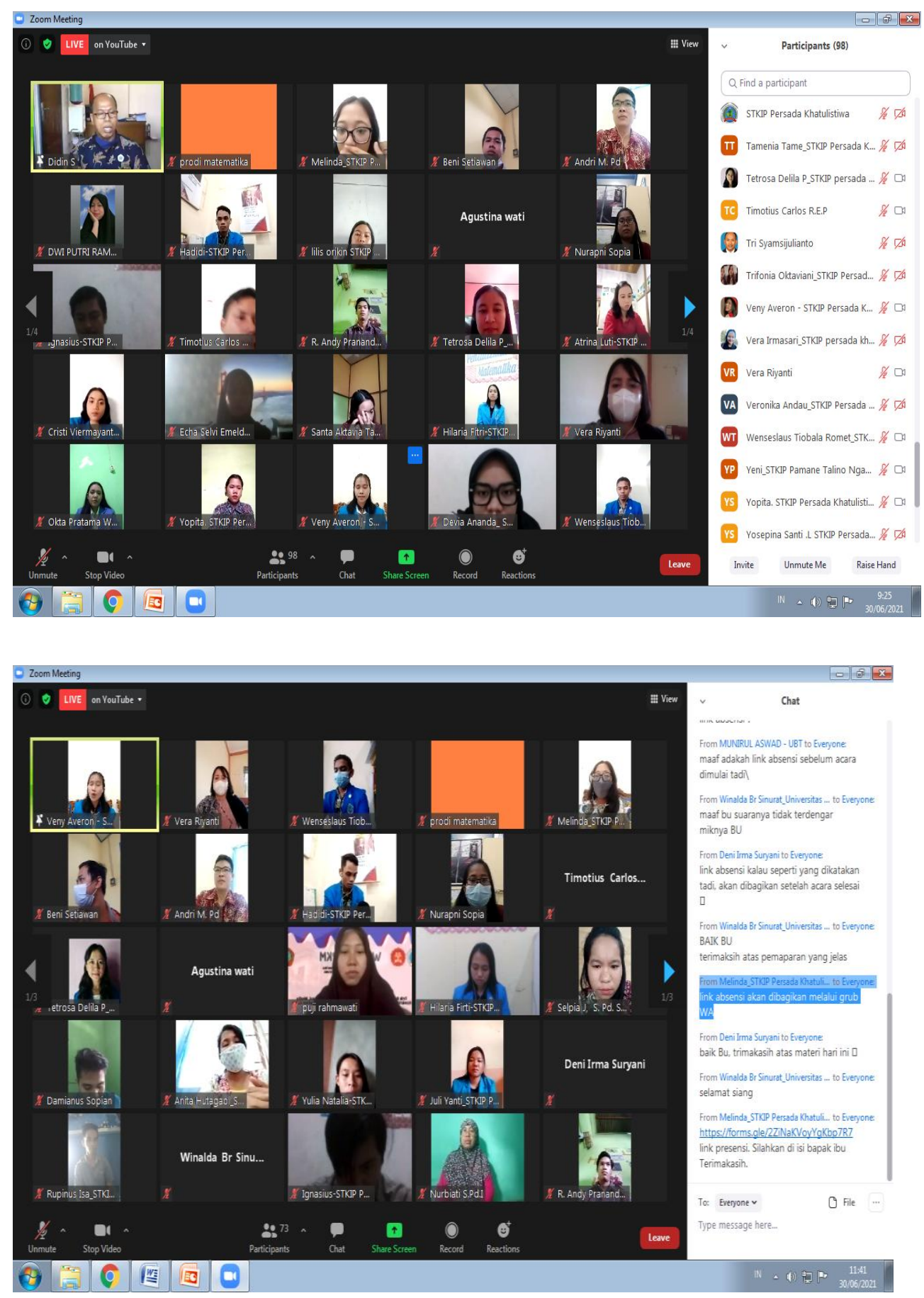

Gambar 7. Sebagian Tampilan Sesi Foto Webinar

Berdasarkan hasil evaluasi yang diperoleh melalui penyebaran angket kepada seluruh peserta webinar, sebanyak $87,7 \%$ peserta dapat dengan mudah memahami materi yang telah disampaikan. Pada sesi diskusi beberapa peserta memberikan pertanyaan dan langsung ditanggapi oleh pemateri. Peserta berpendapat bahwa 98,2\% pemateri menjawab dengan baik. Adapun dampak kegiatan pelatihan kepada guru yakni guru tertarik dan tertantang untuk membuat dan mengembangkan media pembelajaran berbasis animasi. Hal ini terbukti dari kesan dan pesan yang di tulis oleh guru seusai mengikuti pelatihan. Setelah dilakukan pendapimpingan kretivitas guru meningkat terbukti dari hasil media pembelajaran animasi yang telah dikumpulkan.

\section{KESIMPULAN}

Kegiatan Pengabdian kepada Masyarakattelah terlaksana dengan baik dan sesuai dengan tujuan yang diharapkan. Adapun kegiatan dilakukan secara online melalui Zoom meet dengan metode ceramah dan 
demonstrasi. Setelah itu, dilanjutkan dengan pelatihan/praktek pembuatan media pembelajaran berbasis animasi dengan menggunakan beberapa aplikasi. Kegiatan ini berjalan dengan baik dan lancar.

\section{DAFTAR PUSTAKA}

[1] Arjunaita. Pendidikan Di Era Revolusi Industri 5.0. Prosiding Seminar Nasional Pendidikan Program Pascasarjana Universitas PGRI Palembang. 10 Januari 2020.

[2] Pertiwi, D. R. "Pendampingan Pengembangan Kemampuan Story Telling Guru Kelompok Bermain Dan Taman Penitipan Anak Aviciena”. KACANEGARA Jurnal Pengabdian pada Masyarakat, vol.2, no.2, pp. 105-109, Juli 2021.

[3] Nugrahenny, D., Wintolo, H., Kusumaningrum, A., Sudaryanto, S., \& Sajati, H. "Pendampingan Pengenalan Metode Pengetikan Cepat Menggunakan Microsoft Word Bagi Siswa Kelas 5 SD IT Salsabila Al Muthi'in Yogyakarta". KACANEGARA Jurnal Pengabdian pada Masyarakat, vol.2, no.1, pp. 21-28, Juni 2018

[4] Rufaida, H. D. (2018). Pelatihan Berpikir Positif untuk Peningkatan Harga Diri Remaja Panti Asuhan Yatim Putri "X" di Yogyakarta. Universitas Mercu Buana Yogyakarta.

[5] Gurung, R. A. R. "Call It Out: Recognizing Good Teaching and Learning". Journal of Applied Research in Memory and Cognition, vol.9, no.2, pp. 161-164, Februari 2020. https://doi.org/10.1016/j.jarmac.2020.02.003

[6] Henriksen, D., Richardson, C., \& Shack, K. (2020). Mindfulness and creativity: Implications for thinking and learning. Thinking Skills and Creativity, 37(December 2019), 100689. https://doi.org/10.1016/j.tsc.2020.100689

[7] Idris, I., \& Sida, S. C. "Pengaruh Model Problem Based Learning Terhadap Keterampilan Proses dan Hasil Belajar IPS Siswa SD". Indonesian Journal Of Primary Education, vol.3, no.2, pp.58-63, Desember 2019.

[8] Sari, K, R, et.al. "Pengembangan Media Pembelajaran Interaktif Berbasis Articulate Storyline Tematik Terhadap Minat Belajar Siswa Kelas 4 SD”. Jurnal Pedagogi Pembelajaran. vol. 4, no.1, pp 122-130, April 2021.

[9] Rosmiati, M. "Animasi Interaktif Sebagai Media Pembelajaran Bahasa Inggris Menggunakan Metode ADDIE”. Paradigma: Jurnal Komputer dan Informatika Universitas Bina Sarana Informatika, vol.21, no.2, pp. 261-268. September 2019.

[10] Widjayanti, dkk. "Media Pembelajaran Interaktif Berbasis Animasi Pada Materi Statistika Untuk Siswa Kelas 7 SMP”. Jurnal Pendidikan Matematika, vol. 13, no. 1, pp 101-112, Januari 2019.

[11] Feladi, dkk. "Pelatihan Pembuatan Media Pembelajaran Berbasis Animasi Di SMP Negeri 2 Siantan Kabupaten Mempawah”. Jurnal Gervasi. Vol. 1. No. 1, Mei 2017 
